\title{
Building Information Modelling (BIM) Adoption Model for Architectural Education
}

\author{
Ilya Fadjar Maharika ${ }^{1 *}$, Achmad Irsan ${ }^{2}$, Syarifah Ismailiyah Al Athas ${ }^{3}$, Ariadi Susanto ${ }^{4}$, Vendie \\ Abma $^{5}$, Yebi Yuriandala ${ }^{6}$, \\ 1,2,3,4 Department of Architecture Universitas Islam Indonesia Yogyakarta, Indonesia \\ ${ }^{5}$ Department of Civil Engeneering Universitas Islam Indonesia Yogyakarta, Indonesia \\ ${ }^{6}$ Department of Environmental Engeneering Universitas Islam Indonesia Yogyakarta, Indonesia \\ I"maharika@uii.ac.id, ${ }^{2}$ irsan@uii.ac.id, ${ }^{3}$ syarifah.alathas@uii.ac.id, ${ }^{4}$ ariadi@uii.ac.id, ${ }^{5}$ vendie.abma@ui \\ i.ac.id, ${ }^{6}$ yebi.y@uii.ac.id
}

Published: $31^{\text {st }}$ December 2020

The purpose of this study is to design a Building Information Modelling (BIM) integration model for architectural education in adopting BIM culture. Most of the current models on BIM adoption are directed toward the realm of construction industries (consultant firms and contractors) and less on higher education institutions. The discourse on education is mostly concerning experimentation on curricular integration and the lack of general concepts of integration. The main research inquiry of this study is concentrated on which criteria are best suited to the education culture. Utilizing reflective discussion of past experiences and a semisystematic literature review, detailed criteria to capture the multidimensional facets of BIM adoption are proposed. The study proposes the model that offers six main integration criteria: (a) institution vision and priorities, (b) infrastructure, (c) curriculum integration, (d) human resources, (e) knowledge organization, and (f) change management. The application of the model may be limited to architectural schools which are still in the initial process of BIM adoption but the comprehensiveness of the model may possibly be developed as the basis for readiness assessment, roadmap development, and exchange terminologies between education and the wider context of architecture, engineering, construction, operation and management industries.

Keywords: Architectural education, BIM adoption, BIM readiness, BIM integration, BIM curriculum, construction industry 


\section{INTRODUCTION}

The presence of Building Information Modelling (BIM) culture and technology in the fast-changing pace of architecture, engineering, construction, operation, and management - AECOM industries is significantly changing the notion of architectural education. Although the impact of BIM as a major disruption factor in the construction business is still considered debatable, most of the scholars seem to agree that the digitization of design and construction through BIM is one of the important factors to consider in current practice (Ahmad et al., 2016). In many areas of the world, it is obvious that this new technology has already changed traditional or conventional design and construction practices (Schober et al., 2017), causing a fundamental impact on productivity (Poirier et al., 2015), and becoming an assistive knowledge management system to construction processes and activities which are always knowledgeintensive (Wang \& Meng, 2019).

Within this wave of change, there have been many efforts to map the process of general adaptation to BIM culture in various sectors and in many parts of the world (Smith, 2014). These mapping efforts include a conceptual framework based on readiness, capacity and maturity adoption models of BIM implementation in the industry (Succar and Kassem, 2015) and a macro process of BIM maturity practices adoption through comparative market analysis (Kassem and Succar, 2017). Reports also show critical factors that may potentially facilitate architects' adoption of BIM such as management support, individual 3 inclinations towards information technology, compatibility between new technology and the individual's existing experiences as well as computer self-efficacy (Son et al., 2015). For new architects, it is a benefit to be more familiar with the new techniques along with the current architectural culture and sensitivity of the new technology (Cocchiarella, 2016). It is also conclusive that there is a rapid adoption of BIM in the construction world since it became a strategic competition tool in the market and was posited as a catalyst for change in organizational culture (Smith, 2014), including professional development of BIM actors as 'agents of change' (Bosch-Sijtsema, Gluch, \& Sezer, 2019).

From the perspectives of the construction industry, there are many valid expectations in particular toward education namely, the immediate needs of preparing BIM-ready graduates and adapting to the BIM culture for their future work (Smith, 2014) and educating young architect primarily in countries where BIM is still on the process of implementation (Jagiello-Kowalczyk and Jamrozy, 2016). Many studies proposed a current list of recommendations, and challenges, such as infusing BIM-enabled pedagogy and curricula of tertiary education (Succar and Kassem, 2015; Hu, 2019), and adopting project-based education through BIM (Jin et al., 2018). The primary goal is to narrow the gap between construction industries and education. BIM is one of the important keys to bridge this gap because it is believed to be a powerful connection between theory and praxis (Cocchiarella, 2016).

From the education point of view, theoretically, BIM may be a linking factor between these two worlds. However, in educational praxis, some fundamental questions can be raised.

The first query concerns the notion of adoption itself. Studies have comprehensively indicated the level of adoption and maturity implementation of BIM in construction industries (Succar and Kassem, 2015; Kassem and Succar, 2017; Schober et al., 2017). The wide range of those surveys and robust model of maturity concepts invite some critical questions: Why are such assessments and measurements barely reported in academic circles while they are clearly addressing their preparedness, readiness, or adoption maturity. Do these assessments and measurements of BIM adoption actually matter for the future of education? Is there any strong relation between maturity in industry and maturity in education? Can the adoption and maturity model in industry be simply applied into architectural education in particular and engineering education in general? More questions can be raised since the gap may be widening between the pace of praxis-driven BIM adoption in the construction industry and the slow learning process of traditional education.

The second query concerns the notion of the challenges and opportunities involved in BIM adoption to education. Indeed, there is ample evidence from the construction industries that BIM implementation is a challenging process with a variety of experiences, status, approaches and frameworks such as seen in BIM curriculum design (Abdirad and Dossick, 2016), as well as a multitude of drivers and barriers (Babatunde et al., 2018; Babatunde and Ekundayo, 2019). Learning 
from the industry, education may also have its own challenges. The initial work of Olowa et al. who reviewed fifty-one cases of BIM education confirms various education challenges to adopt BIM (Olowa et al., 2019). Accordingly, what is important in industries may be the same or may be different with in its education counterparts. If the industries have already prepared a list of criteria of success - and failure - then we also may infer that the educational 4 institutions may also have their own criteria. Research and reports of BIM implementation in engineering education, especially in architectural education are currently available as we revealed in this study. But unfortunately, they lack a general model of the conceptual framework for adoption in the education domain. The studies are also not directed to conceptualize the criteria that can be generally used to depict the 'big picture' of adoption of BIM in higher education. We believe that this broader portrayal of BIM adoption in education is an important key to enter into the new culture of architectural education in particular and engineering education in general. The bibliometric search and scientometric analysis recently conducted by Jin et al., showing how BIM was applied in construction engineering and management, has also revealed that the industry, academics, and governmental authorities should collaborate. The collaboration is needed to recognize the current needs, limitations, and trends of BIM application in the construction industry which can then be applied in conducting research to find the best ways for improvement. Jin et al. strongly recommended that BIM pedagogy-based research should be shared among the academic community to keep the BIM education updated. It is also necessary to explore practical experience and local BIM culture to bridge the gap between educational goals and industrial needs (Jin et al., 2019).

The purpose of this paper is henceforth twofold. The first is to propose a design of a BIM integration model for architectural education in adopting BIM culture. The second is to map the criteria important for education which may be used as a guideline to develop a comprehensive roadmap for BIM adoption. This study proposes several practical implications. For education institutions, the model may capture institutions' level of BIM adoption in order to develop various analyses (comparison/contrast, success/failure factors) within or among institutions. The model and criteria may also be deployed as the basis for self-evaluation as well as policy development using a systematic roadmap of BIM adoption in education institutions. As most of the models of BIM adoption level are directed toward players in the construction industries (consultant firms and contractors), this study that focuses on architectural education as the subject will be a novel contribution to the discourse of BIM adoption and may also be applied to the wider context of AECOM education. While the model we propose can be seen as a generic concept, the relevance may be limited since the study was conducted in Indonesia, which is posited as an entry level country in BIM adoption. Nevertheless, viewing this process from the entry level stage of BIM adoption gives us an opportunity to reveal more on the challenge of initial barriers of adoption, while at the same time, we can learn from the success stories and mature adoption examples available in many current reports.

\section{RESEARCH METHODS}

As an effort to develop the model of BIM adoption in architectural education in particular and engineering in general, a mix of research methods has been applied. A reflective study of our own university experiences in BIM adoption was conducted through continuous internal discussion to formulate the model. From the current body of literature, the general concepts of BIM adoption were reviewed to reiterate and refine the proposed model. To elaborate the model to the level of criteria, we conducted a semisystematic literature review of references, collected and selected from two authoritative indexing platforms: Scopus (in https://www.scopus.com) and Web of Science (through Taylor \& Francis 5 portal at https://www.tandfonline.com). Our review did not pursue a quantitative profiling of the literature, but instead we sought the important insights relevant to BIM adoption in education. Within the range of August 2019 to March 2020, we conducted the reference query of current literature using the search strings that included: \#BIM, \#architecture, \# adoption, and \#readiness, in titles, abstracts, and keywords in various combinations. To illustrate the scope of the exploration, when we searched combining all strings of entries of \#bim \#architecture \#education and \#readiness in Scopus, it did not result in any single paper while in Taylor \& Francis with the same string the search revealed 175 articles. Through screening by relevance in the title, meaning having close relation to the education domain, the relevant articles were reduced to only 
seven articles. With search string \#BIM, \#architecture, \#education, the search in both portals resulted in 57 articles but then the relevant articles were reduced down to 41 articles. Furthermore, the query using search string \#BIM, \#architecture, \#education, \#adoption resulted in 10 articles. After discounting some duplicated findings, we identified the relevant articles as described below in sub chapter 4 . The review was aimed to see the important and relevant criteria in the development of models for adoption of BIM in architectural education. To gather a wider perspective from the key actors in the Indonesian context, we conducted two expert focus group discussions (FGD). The first FGD was aimed to develop the concept of BIM adoption and identify the important key criteria. The discussion was held as a side event of the International Conference on Education Architecture in Asia 2019 (26 September 2019, held in the Department of Architecture, Universitas Islam Indonesia UII) involving experts on BIM representation of Institute BIM Indonesia (IBIMI) and BIM implementers from construction enterprises and related researchers. The second FGD was aimed to examine and refine the proposed criteria. The event was hosted by the BIM Center of Excellence involving experts and representatives from IBIMI, regulators (Board of Construction Development, Ministry of Public Works and Housing), contractors, architectural consultants, educators, and students. This activity was held on 22nd of November, 2019 in the Growth Hub of Universitas Islam Indonesia.

\section{RESEARCH FINDINGS AND MODEL DEVELOPMENT}

\subsection{Defining General Concepts of BIM Adoption in Education}

In defining the general concepts of BIM adoption in education, we conducted a reflective study on the experience of our Department. The Department of Architecture at UII has committed its vision to introduce computational learning since 1998 through computational graphics training. The following initial steps included the adoption of Computer Simulation and Presentation as a compulsory course in 2001 and formalization of the Digital Architecture Laboratory as the authorized Autodesk Training Center in 2005. Since 2010, the Laboratory started to adopt ArchiCAD, which can be considered as the initial version of BIM. The initiative to develop a project-based design studio utilizing ArchiCAD as the media was piloted since then. In 2013, the curriculum formalized the model in which it became compulsory for students to have the ability to operate BIM. The school introduced BIM in the third semester and this was followed by step-by-step integration in succeeding architectural studios. The utilization of BIM culminated in the Architectural Design Studio 6 (third year second semester) in which students are grouped to run an integrated project. For the following studios (fourth and fifth year) BIM became compulsory tools to produce the technical drawings of the design. This continuing successful implementation process was 6 praised by the Korea Architectural Accrediting Board (KAAB), a member of the Canberra Accord when they awarded international accreditation to the department. In 2018, the Faculty of Civil Engineering and Planning founded the BIM Centre of Excellence in a plan to integrate the effort for BIM adoption into all three departments (architecture, civil engineering, and environmental engineering). The newest effort to integrate BIM into the learning culture was done during the formulation of the Architecture and Civil Engineering new 2020 curriculum. In architecture, in particular, the new curriculum introduces computational thinking and programming from the first year, following BIM authoring software training, with integration into more design studios in the second to fourth year, as well as utilizing it for project coordination and integrated project delivery courses in the fifth year. BIM culture has become a backbone for the new curriculum's learning outcomes responding to the new business and technology in construction industries. In terms of organizational change, the school has started to develop a comprehensive roadmap of BIM adoption that covers many aspects of management and policy as well as organizational development. From the above brief historical trajectory, through the series of expert FGDs, we recognized that the Department followed - unintentionally - the trajectory towards the BIM adoption model that was already formulated namely, preparation, participation, and innovation (Succar and Kassem, 2015). Succar and Kassem in their comprehensive study of macro adoption defined adoption as a concept that combines BIM implementation in a certain unit of organization and BIM diffusion to other units within the organization or other parties on various scales. Under the umbrella term of BIM implementation, the study showed an organizational status that may consist of three-phases: the readiness to 
adopt, the capability to perform, and the maturity of performance for BIM implementation. BIM readiness is the pre-implementation stage representing the tendency of an organization to adopt BIM culture, tools, workflows, and protocols. This means that readiness is the initial stage of a long process of BIM adoption expressed in the initial preparation, the potential to participate, and the capacity to innovate. After the state of readiness is achieved, an organization may have a BIM capability that is a deliberate implementation of BIM culture to deliver measurable outcomes. Applying this capability strategically, an organization may achieve their goals of maturity through well-defined stages such as object-based Modelling, model-based collaboration, and network-based integration which covers many technologies, processes, and policy topics. BIM maturity is a postimplementation stage showing gradual and continual improvement in quality, repeatability of the process, and predictability of the output while the outcomes within available capabilities are expressed as maturity levels. Reflecting back to the historical trajectory of our Department, we saw that the model developed by Succar and Kassem can be a 'good fit' for education institutions. Expanding more on the initial stage of preparation in our Department, we saw specific aspects including the vision, priorities of the institution, and infrastructure supported by financial commitment were the keys to success in this entry-level adoption. These early indicators of success were also confirmed from the context of industries such as shown by the study conducted by Gilkinson et al. (2015). The study saw that the vision of an institution was an essential key although the BIM adoption in this industry was driven by the need to be competitive in the market, to reduce costs and time, and to satisfy the government regulations. The BIM infrastructure is of great concern because of the working environment created by the 7 chosen system as well as its financial consequences. Hence, to decide the choice of infrastructure sometimes even requires a BIM consultant. Indeed, BIM has a comprehensive capacity to integrate design applications, clash analysis, quantification, scheduling, simulation, and visualization. The system also includes the capabilities of life-cycle costing, environmental analysis, energy use, auditing of models, management of life-cycle information through facility management systems, and self-reporting software. BIM technology is now able to control and measure the in-situ progress of work projects at the site. All of these advancements are important resources, and for Gilkinson et al., all are essential in the BIM adoption process. Moreover, the human resources that are an indication of an organization's capacity also depend on the availability of people with the specific capacities as BIM modeler, BIM manager, BIM coordinator, and the BIM implementation manager (Gilkinson et al., 2015). Furthermore, in the stage of participation of the teaching and learning process, we considered the development of curricula such as training modules and assessment tools while managing human resources especially the trained staff as the vital keys to the operation. We will elucidate more on these in the following sections of the paper. Finally, in the stage of innovation, we believe that it could only be achieved through the capacity of the institution to develop knowledge through other organizations and to manage continuous change through internally driven innovation and external outreach development. However, referring to the model of BIM implementation which represents the successful adoption of a system/process by a single organization, our Department has not yet entered the stage of BIM diffusion. From the model, the diffusion stage represents the spread of the system/process within a population of adopters such as in a certain network of organizations or units for example, in a country (Succar and Kassem, 2015). However, for our context, the establishment of the BIM Centre of Excellence in 2018, may represent a starting point of contribution toward the university-wide adoption of BIM. The membership to Institute BIM Indonesia and our appointment as official partner of the Board of Research and Development, Ministry of Public Works and Housing on BIM were two initial steps in the stage of BIM diffusion. Outlining back and forth from our reflective study of the historical trajectories of the Department and the theoretical framework of the BIM adoption model proposed by Succar and Kassem (2015), it appears that they confirmed each other. Conceptually, we firmly believe that the model may be used as the basis for developing an applicable BIM adoption model in education institutions nationally and quite possibly, globally.

\subsection{Outlining BIM Adoption Criteria in Education}

In seeking the dimensions of the BIM adoption, the historical reflections provide the insight that the concept is closely related to the readiness of 
the internal process of an organization to achieve their goals and the institution's key performance indicators to measure those goals according to specific strategies and priorities. Readiness is associated with people's responses to deal with organizational change as indicated by the study of Armenakis (1993). Readiness to adopt something new can be measured from various perspectives and it is possible to build psychometric properties of readiness instruments (Holt, 2007). The studies of Holt, Armenakis and others offer five main factors of readiness at the individual level consisting 8 of: (a) discrepancy (such as answering a question of the belief that a change was necessary), (b) efficacy (the belief that the change could be implemented), (c) organizational valence (the belief that the organization may benefit from the change), (d) management support (the belief that the organizational leaders are committed to the change), and (e) personal valence (the belief that individual persons may also earn benefit from the change) (Holt et al., 2007). The concept of readiness of adoption may refer to various levels, namely individuals, teams, or organizations. In our study, readiness towards BIM adoption refers to the concept of readiness at the organizational level as indicated in the theory of organizational readiness for change. It has to do with a shared psychological state in which organizational members feel committed to implementing the change (change commitment) and confidence in their collective abilities to do so (change efficacy) (Weiner, 2009). In regards to $\mathrm{BIM}$, readiness of this adoption was very much supported by internal willingness such as competition motivation but was also strongly influenced by governmental policies, financial incentives, and technological support (Juan et al., 2017). Furthermore, Greef and Ghoshal identified that readiness comprises six characteristics, namely: (a) organization ability to define and prioritize problems, (b) infrastructure and applications to support dynamic initiatives, (c) use of information and knowledge, (d) ability to manage and implement key performance indicators via formal system development and project management processes, (e) trained and skilled members, and (f) effective change of management processes to modify practices and behavior (Greef and Ghoshal, 2004). Moreover, adoption to something new, such as BIM culture, is also closely related to the inclination of an organization to change towards innovation. In this aspect, Lokuge et al., who conducted a study of organizational change for information technology innovation, highlighted two views on the matter namely, readiness of an organization to withstand an innovation and the readiness of an organization to enable innovation. Looking more on the second view, Lokuge's study identifies 21 aspects of measurement namely, attitudes, psychological motivation, empowerment, flexible financial support, flexible human resources, flexible infrastructure, the stability of the economic status, digital technology availability, infrastructure stability, knowledge on technology, process and organizational support, skills of staffs, adaptability to a variety of projects, sharing ideas, decentralized decisions, risk aversion, clarity of goals and vision, the relevance of goals, communicating goals and strategic directions, software vendors, management consultant, and customers/suppliers. Those aspects are categorized into seven aspects. The first aspect is resource readiness, which covers aspects of organizational needs for finances, human resources, and technology. The second is cultural readiness which includes ways of sharing ideas and thoughts, decentralized decision making, and sufficient risk assessment in anticipating innovation and change. The third is strategic readiness which refers to the clarity of goals, relevance, and good communication to all stakeholders. The fourth is information technology readiness which refers to the reliability of the system, stability of access, and reliable technology and infrastructure. The fifth is innovation valence which refers to staff who have the 'right stuff', motivation, and are empowered to make decisions. The sixth is cognitive readiness which shows the adequacy of staff in terms of knowledge, skills, and adaptation to innovation. Finally, the seventh is a readiness for partnership that refers to the strength of the network of vendors, consultants, and suppliers in supporting innovation (Lokuge et al., 2019). 9 Framing by applying the readiness concepts (Greef and Ghoshal, 2004) and learning from the clusters of aspects (Lokuge et al., 2019), we developed a map of indicators resulting from the series of expert FGDs (Table 1). We modified Greef and Ghoshal's frame to fit more with education culture. Specifically, (a) The aspect of organization ability to define and prioritize problems was modified to "vision and priorities of the institution"; (b) The aspect of infrastructure and applications to support dynamic initiatives was modified to "infrastructure and resources"; (c) The aspect of use of information and knowledge was modified to be more specific as "curriculum and training modules"; (d) The aspect of ability to manage and implement key 
performance indicators via formal system development and project management processes was modified into "organization and management"; (e) The aspect of trained and skilled members, we modified to "human resources;" and finally, (f) effective change of management processes to modify practices and behavior, we modified to "change management."
Our important FGD results revealed aspects that were shared by all members of the group: representatives from IBIMI, regulators, contractors, architectural consultants, educators, and students. They are summarized below in the Table 1.

Table 1. Scale of importance of aspects according to member discussion

\begin{tabular}{|c|c|c|c|c|c|c|}
\hline Key aspects & 1 & 2 & 3 & 4 & $\begin{array}{l}\text { Weighted } \\
\text { value }\end{array}$ & proposed keywords \\
\hline trained staffs for teaching and learning & 0 & 0 & 4 & 6 & 36 & trained educators \\
\hline $\begin{array}{l}\text { vision of BIM as part of strategic } \\
\text { plans }\end{array}$ & 0 & 1 & 4 & 5 & 34 & strategic plan \\
\hline $\begin{array}{l}\text { action plans and consistent } \\
\text { implementation }\end{array}$ & 0 & 1 & 5 & 4 & 33 & action plan \\
\hline budgeting plans and sustainability & 0 & 0 & 8 & 2 & 32 & sustainable budgeting \\
\hline $\begin{array}{l}\text { organizations supporting } \\
\text { implementation }\end{array}$ & 0 & 2 & 4 & 4 & 32 & unit establishment \\
\hline $\begin{array}{l}\text { strengthen graduate } \\
\text { competencies through certification }\end{array}$ & 0 & 3 & 3 & 4 & 31 & $\begin{array}{l}\text { certification and alumnae } \\
\text { support }\end{array}$ \\
\hline $\begin{array}{l}\text { socialization and dissemination to all } \\
\text { members }\end{array}$ & 0 & 2 & 5 & 3 & 31 & convincing members \\
\hline $\begin{array}{l}\text { convince universities/ } \\
\text { corporations/ highest management }\end{array}$ & 0 & 3 & 3 & 4 & 31 & management commitment \\
\hline $\begin{array}{l}\text { information technology infrastructure } \\
\text { for teaching and learning }\end{array}$ & 0 & 3 & 4 & 3 & 30 & basic infrastructure \\
\hline $\begin{array}{l}\text { integration courses or modules in } \\
\text { learning }\end{array}$ & 0 & 2 & 6 & 2 & 30 & modules and courses \\
\hline teaching and learning quality assurance & 0 & 3 & 4 & 3 & 30 & quality assurance \\
\hline infrastructure collaborative BIM & 0 & 3 & 5 & 2 & 29 & $\begin{array}{l}\text { infrastructure for } \\
\text { collaboration }\end{array}$ \\
\hline sustainable learning programs & 0 & 5 & 2 & 3 & 28 & integrated curriculum \\
\hline research and development & 0 & 4 & 4 & 2 & 28 & research and development \\
\hline create external support & 0 & 4 & 5 & 1 & 27 & ecosystem for innovation \\
\hline action plan to manage innovation & 1 & 3 & 4 & 2 & 27 & managing innovation \\
\hline $\begin{array}{l}\text { services outside teaching/ learning or } \\
\text { outside institution }\end{array}$ & 0 & 5 & 4 & 1 & 26 & outreach service \\
\hline systematic assessment system & 1 & 3 & 3 & 2 & 24 & assessment system \\
\hline
\end{tabular}

(Note: 1: not important; 2: less important; 3: important; 4: very important) 
There were other aspects that also can be raised from the expert discussions but which were considered insignificant in term of quantification (less than 10 in weighting value). These delisted aspects can be included as the external drivers of BIM adoption. With these in mind, Ahmed and Kassem's broad survey of BIM implementation in 177 companies in the United Kingdom found that the adoption drivers can be categorized into two main drivers namely, internal and external. While the former includes top management support, organizational readiness for communication behavior, financial resources and perceived costs, social motivations, organizational culture, willingness/ intention, and organizational structure and size, the latter covers coercive pressures/forces (such as the mandate of the government), mimetic forces (such as imitating the success of other organizations), and normative forces (such as parts of an organization's strategy) (Ahmed and Kassem, 2018). From the FGD members who are regulators, they emphasized the need of national board of certification of the competencies and training, the importance of benchmarking to outside countries, and legalization of the mandate on the national level. From the industries, especially from contractors, they emphasized the importance of market creation that conforms to BIM culture including the priorties to educate the project owners' vision of BIM, and the praise to the regulators (Ministry of Public Works and Housing) to initiate BIM platform for the Indonesia context. They also encouraged us to create a network for national construction companies in order to create a healthy ecosystem of BIM to include all actors namely, from students to industry players, and including owners and investors. Aside from the above aspects, the members from architectural firms suggested the importance of designing curriculum together with industry, upgrading the current vision of lecturers, tutors, and facilitators on technical and non-technical aspects of BIM, and encouraging adoption in the field of mechanical and civil engineering 'best practices' altogether to create more interprofesional education. From the above elaborations, we came to the belief that our proposed six criteria were supported by the references. In addition to this shared vision, we saw that all six criteria can also be arranged into the three stages of the BIM adoption process (Table 2). The first step is the preparation of the organization's commitments in which vision, priorities, and infrastructure are the key steps. The second step is the implementation of the education process for which curriculum development and availability of trained personnel or staffs are the key factors. The third step is the development of the internal capacity of innovation and outreach advancement. This final step is supported by an established organization to manage knowledge within the education environment and the change management to include all members in the innovation and outreach, and network development. These three steps may represent the ladder of maturity of BIM implementation in higher education.

Table 2. Map of key criteria for the ladder of adoption maturity

\begin{tabular}{|l|l|l|l|l|l|l|}
\hline \multirow{2}{*}{$\begin{array}{l}\text { Level of } \\
\text { Adoption }\end{array}$} & \multicolumn{3}{|l|}{ Proposed Criteria, modified from Greef and Ghoshal (2004) } \\
\cline { 2 - 7 } $\begin{array}{l}\text { (Modified } \\
\text { from (Succar } \\
\text { and Kassem, } \\
\text { 2015) }\end{array}$ & $\begin{array}{l}\text { vision and } \\
\text { priorities of } \\
\text { the } \\
\text { institution }\end{array}$ & $\begin{array}{l}\text { Infrastructure } \\
\text { and resource }\end{array}$ & $\begin{array}{l}\text { curriculum } \\
\text { and training } \\
\text { modules }\end{array}$ & $\begin{array}{l}\text { human } \\
\text { resource }\end{array}$ & $\begin{array}{l}\text { organization } \\
\text { and } \\
\text { management }\end{array}$ & $\begin{array}{l}\text { change } \\
\text { management }\end{array}$ \\
\hline $\begin{array}{l}\text { Preparation of } \\
\text { organization } \\
\text { commitment }\end{array}$ & $\begin{array}{l}\text { strategic } \\
\text { plan }\end{array}$ & $\begin{array}{l}\text { basic } \\
\text { infrastructure }\end{array}$ & $\begin{array}{l}\text { modules } \\
\text { and courses }\end{array}$ & $\begin{array}{l}\text { trained } \\
\text { educators }\end{array}$ & $\begin{array}{l}\text { unit } \\
\text { establishment }\end{array}$ & $\begin{array}{l}\text { convincing } \\
\text { members }\end{array}$ \\
\hline $\begin{array}{l}\text { Implementatio } \\
\text { n of educational } \\
\text { processes }\end{array}$ & action plan & $\begin{array}{l}\text { infrastructure } \\
\text { for } \\
\text { collaboration }\end{array}$ & $\begin{array}{l}\text { integrated } \\
\text { curriculum }\end{array}$ & $\begin{array}{l}\text { students } \\
\text { support }\end{array}$ & $\begin{array}{l}\text { quality } \\
\text { assurance }\end{array}$ & $\begin{array}{l}\text { management } \\
\text { commitment }\end{array}$ \\
\hline $\begin{array}{l}\text { Innovation } \\
\text { capacity and } \\
\text { outreach } \\
\text { advancement }\end{array}$ & $\begin{array}{l}\text { sustainable } \\
\text { budgeting }\end{array}$ & $\begin{array}{l}\text { outreach } \\
\text { service }\end{array}$ & $\begin{array}{l}\text { assessment } \\
\text { system }\end{array}$ & $\begin{array}{l}\text { alumnae } \\
\text { support and } \\
\text { certification }\end{array}$ & $\begin{array}{l}\text { research and } \\
\text { development }\end{array}$ & $\begin{array}{l}\text { ecosystem for } \\
\text { innovation }\end{array}$ \\
\hline
\end{tabular}




\section{DISCUSSION: EXPANDING THE MODEL}

Learning from the discourse of BIM adoption in industries, there are many interrelated terms and concepts which are often used interchangeably in the context of BIM such as implementation, diffusion, readiness, and adoption. Researchers also comprehensively compile adoption roadmaps that indicate the aspect of learning and education as an important element in policy development for the adoption of BIM. The main task of education and learning is to build competencies, education frameworks, learning modules, and awareness among all contributors in the supply chain, including educating teachers (Kassem and Succar, 2017). From our semisystematic survey of the literature, we tried to categorize these essential aspects into the six proposed criteria we have developed to deepen the dimension of the model.

\subsection{Vision and Priorities}

In this general view of BIM adoption, both the expert discussion members and references agreed about the importance of the vision and priorities of the institution. Adding further dimension to these core criteria, the institution can develop the vision of BIM as part of its strategic development plans. Through identifiying problems internally, they can formulate action plans for BIM and should consistently implement them. In doing so, the institution has to prioritize BIM on budgeting plans and maintain the program's sustainability. In the references, this dimension was indicated by the need to include BIM in strategic planning of engineering companies as well to propose BIM for building knowledge Modelling (Gilkinson et al., 2015). Further study also indicated the six areas required for BIM to be inclusive in the frame work were namely: collaborative curricula, space, teamwork, relevance to industry, technical/ technological skills, and the role of professors/ lecturers (Shelbourn et al., 2017).

\subsection{Infrastructure}

To initiate BIM adoption in education, the institution has to establish a basic but sufficient information technology infrastructure (such as BIM in stand-alone computers) to implement BIM for teaching and learning. Some studies have reported the importance of this dimension and development of the basic 12 infrastructure.
Initiating implementation of digital media in design must also cope with polarization between traditional and digital media and the pressing needs for multidisciplinary integration and the development of multimodal and media-rich environments (Angulo, 2007). The more mature institutions will show sufficient infrastructure to implement collaborative BIM teaching and learning (for instance BIM in a network of computers) including financial resources to manage them. In this aspect, some research confirmed that BIM can also become a platform for multifaceted learning in globally distributed teams and to develop experiential educational settings internationally (Dossick et al., 2015). It was recently reported that the online learning platform of BIM was a positive learning experience for both students and instructors (Suwal and Singh, 2018). Readiness in infrastructure will also require the ability to combine technical depth and integrated multidisciplinary collaboration on BIM learning, integrated project delivery to meet specialized skills and professional standards, and a consistent focus on the practice-based environment (Solnosky et al., 2014, 2015). The selection of technical tools for functional requirements and needs, as well as non-technical issues are also important stages in developing BIM adoption in which collaborative initiatives have a vital role (Gu and London, 2010). Some experimentation in terms of advanced infrastructure was also conducted such as introducing building interactive Modelling which complements the capabilities of BIM with social interaction $(\mathrm{Ku}$ and Mahabaleshwarkar, 2011), semantic web technology linked to BIM for architectural heritage (Simeone et al., 2019), and virtual BIM reviewer (VBR) as a tool for global collaboration in practice (Wu et al., 2019). The most mature institutions will enable their infrastructure and resources to implement BIM technology outside of teaching and learning such as for outreach services and collaborations with the industry as well as facility management of the campus itself, through integrating BIM with the geographical information system and infrastructure (Wang et al., 2019).

\subsection{Curriculum}

The core adoption pathway for higher education is the development of the curriculum. Most of our reviewed references were focused on this particular part of the proposed criteria. As early 
as 2011, from the references, we saw that the integration of BIM pedagogy is the key factor (Becerik-Gerber et al., 2011). There was also a tendency of architecture schools to fully integrate BIM in the curriculum while schools of construction tended to only use 4D and 5D (scheduling and estimating) (Joannides et al., 2012). BIM may also be useful for the vertical integration (an upper and lower division of students). Such integration would further promote the use of BIM tools and create a deeper understanding of information management (Ghosh et al., 2015).

There are various ways and degrees of integration available (Nushi and Basha-Jakupi, 2017). Many of references were also directed to show the regional experiences such as academic readiness for BIM integration in the Malaysian context (Yusuf et al., 2017), and the practice of BIM as a digital collaboration platform for students in the cross-disciplinary design teams through information sharing in China (Jin et al., 2018). Moreover, they showed that students gain valuable experience from project-based collaborations with BIM capabilities which support future employment skills within the AEC job market. In the process, the integrated design approach was embedded and showed a strong link between academic activities and real-world industrial practice, including the interoperability of building information exchange among different digital platforms (Jin et al., 2018). Integrating BIM in a teaching technology platform (BIM-enabled pedagogy) will also provide a novel pedagogical approach and give more positive evidence of its effectiveness than in traditional courses in an architecture curriculum (Hu, 2019).

While in the initial entry phase of the adoption, the institution may formulate learning objectives and learning plans and develop courses/ modules that integrate BIM in the curiculum. The processoriented teaching approach in the project-based course is strategic entry point to understand BIM (Wang and Leite, 2014). References indicated that some new competences should be introduced: for example, the Industry Foundation Classes (IFC) data model that intended to describe architectural, building and construction industry data and integrated design for both lower and upper students (Ahn and Kim, 2016), and the effectively used BIM execution plan (BEP) (Wang and Leite, 2014). Furthermore, this BIM execution plan constructs a roadmap throughout the project's life-cycle of construction management for students, enriching the learning methodology of the BIM itself not only its technology (Leite, 2016), and emphasizing the interoperable activities (teamwork, software, and database organization) as the fundamental principles in the curriculum (Nushi and BashaJakupi, 2017), along with interdisciplinary collaboration including the skills of data transfer and interoperability (Filzmoser et al., 2016). Moreover, curriculum integration was recommended at least for three semesters (Nushi and Basha-Jakupi, 2017).

For full implementation of the integration, we believe that the institution should conduct a sustainable working system for training such as in regular training schedules, with consultative assistantship to students, including developing a feedback mechanism from students for program improvements. One example in a recent study showed positive feedback from students about BIM integration into the curriculum (Rosli et al., 2016). The curriculum integration may also be advanced by creating interoperability of different digital platforms within the institution as well as with the AEC industry. The platform may provide direct professional advice to improve the constructability of students' design work. There will also be the need for realignment of education programs concerning the emerging use of BIM through distance learning, collaborative learning, and industry collaborations (Jin et al., 2018, 2019).

The criteria of curriculum must also involve the process of integration. References have already given several indications. Huang proposed threelevels of framework in construction management curriculum, namely: fundamental level (BIM knowledge and contents), application-level (realworld problem solving), and advanced level (latest and advanced BIM technology) (Huang, 2018). Palomera-Arias and Liu have also described the three-levels framework of integration of BIM into courses and laboratory exercises of Mechanical, Electrical and Plumbing (MEP) curriculum namely: BIM software package (introduction), MEP laboratory exercises, and BIM for final capstone project (PalomeraArias and Liu, 2016). We saw that both frameworks could complement each other. Abdelhameed proposed that the pedagogical curriculum of capstone design studios should include BIM-related software to introduce fundamental knowledge and environmental 
analysis to develop a better design in the conceptual phase. Moreover, through a deeper exploration of BIM and related software in building systems, acoustic and insulation, and illumination and daylighting, for instance, students will have practical examples to apply in more specialized courses (Abdelhameed, 2013). Abdirad and Dossick analyzed the strategy towards BIM adoption and the implementation in curriculum design, such as in teaching-learning methods, timelines, contexts, and learning strategies. The strategy became important to determine the type of supports for students, determine the type of course whether as an elective or compulsory, tutorial methods, and designing methods of assignments and their criteria. It is noteworthy that competencies and skills for industrial engagement are important factors in this aspect of curriculum integration (Abdirad and Dossick, 2016).

References have also indicated a variety of uses of BIM in education and its relation with industry. As early as 2010, Sacks and Barak recomended that BIM can be used as a learning tool for project teams to be more familiar with construction tasks before commencement in the field (Sacks and Barak, 2010). BIM may also provide a learning tool in real-life construction tasks giving both academic and practical value ( $\mathrm{Lu}$ et al., 2013), experience in the new work environment and communication process (Brokbals and Čadež, 2017), and experience in the use of collaboration and coordination learning modules for BIM education in different programs (Bozoglu, 2016). BIM execution plan can also be applied for project-based learning integration in capstone and real-world projects (Zhang et al., 2018). The advancement of BIM in the curriculum will also address the need for sustainable design including in the analysis of multiple criteria during construction, operation, demolition, and recycling (Jagiello-Kowalczyk, 2017), in the phase of creating conceptual mass in the design studio (Bilgehan İyican et al., 2015), and integrating environmental analysis employing $\mathrm{BIM}$ in the conceptual phase to help students to improve design quality (Abdelhameed, 2018).

Within these curriculum criteria alignment and assessment system are important. References have also indicated some challenges such as the awareness of the technology, curriculum and training modules (Succar and Kassem, 2015; Kassem and Succar, 2017), as well as how to align universities' educational goals with BIM- related courses (Uhm et al., 2017). Abdirad and Dossick comprehensively outlined critical areas in education, namely: (a) incorporating BIM to curricula through a variety of strategies, (b) enrollment of students relevant to strategies including BIM as an optional course, (c) defining required competencies and competency levels, (d) pedagogical strategies for BIM teaching-learning concept, (e) variety of tutoring method (instruction, hands out, audio-video tutorials, interactive simulation, etc. (f) industry engagement and faculties contribution, and ( $\mathrm{g}$ ) variety - fitness of the assessment types, methods, and criteria (Abdirad and Dossick, 2016).

\subsection{Human Resources}

References have indicated that human resources, trained staff and lecturers as the educators and the students were also key criteria for BIM adoption. Trained educators and supporting staff members for the successful implementation of BIM teaching and learning must be prepared, as well as provide availability of schemes to strengthen their competencies in the skills. Educators must explore and develop new methods based on multi-dimensionality of BIM, data-driven, metathinking and skill-building including addressing BIM design studio challenges to reconcile the tradition of abstraction with the synthetic simulation (Ambrose, 2007, 2012). BIM may also open the new challenge for educators to leverage students' level of knowledge and skills while barriers are still present, including the relative lack of reference material, model development not following construction sequence, lack of error detection, and limited choice of component databases. Educators should also notice that students prefered to use BIM more than CAD especially for user-friendliness, help functions, and ability of self-detection of mistakes of the modelling (Deniz, 2018). From students' experience, BIM may help them to learn more quickly and be able to better understand and create complex designs (Wong et al., 2011). Educators will also be required to promote codesign models that work with uncertainties, risks, and failures to cope with the rapid changes in the professional roles in the built environment (MacLaren et al., 2017). At the same time, it will be necessary to explore future pedagogical research in adopting BIM in different project sectors (e.g., building and infrastructure), and to create innovative pedagogical delivery methods to bridge the gap between students and professionals (Zou et al., 2019). 
Concerning students' perspectives, references revealed that BIM adoption and implementation may fill the gap in the rapid growth of the BIMrelated job market but also will need incentives to encourage students to commit to a BIM-oriented career path (Wu and Issa, 2014). In regards to BIM's usefulness, most students desired BIMrelated jobs, and despite the challenges during BIM implementation, there are also indications that students favored BIM-based jobs related to engineering design and project management, and they perceived BIM to be less useful in assisting facility management and quantity survey (Zou et al., 2019).

\subsection{Knowledge Organization}

Based on our experiences, we believe that adoption of something new, such as BIM culture, should be initiated as a process from a small scale unit, which can show success stories, and then convince the larger audience for recognition and diffusion. The unit, either in the shape of a laboratory, independent center of excellence, or departmental level, is vital in order to create sustainable support for implementation of the BIM in any curriculum, in part or as a whole. Organization is also important to create a viable education knowledge ecosystem that acquires competencies for leadership and business development which are equally important for faculty and for students (Aksenova et al., 2019). Within the framework of organizing the knowledge of BIM, institutions may develop criteria, standards, and procedures for BIM teaching and learning with strict quality assurance across modules, courses, and study programs. Once the level of organization is reached, the institution may also develop their capacity both internally and collaboratively for BIM research and development. In a closer look, a collaboration between large institutions and small institutions turned out to be one of the success factors (Abuelmaatti and Ahmed, 2014, 2018).

References have reported many facets of research and development based on BIM culture. As early as 2011, the foresight of integration of BIM and gaming technology to create a framework for design education has been indicated (Yan et al., 2011). Recent studies showed that BIM extended with augmented reality (AR) and virtual reality (VR) may increase student learning and knowledge on building science principles (Vassigh et al., 2020) and has become an emerging trend opening collaboration between designers, instructors, engineers, and computer experts (Diao and Shih, 2019). Applications of BIMenabled VR and AR on construction, engineering education, and training are also future research areas and can be used in the variety of expertise such as in the education of architectural visualization, design, structural analysis, and in the training of safety, use of the equipment, and managing operations of construction sites (Wang et al., 2018). In a larger view, BIM is a step toward the many futures of Computational Design (CD) such as generative design, morphogenesis, etc. This future portfolio may differ significantly from the previous traditions since the ground of design representation in computational logic will be on the data and information instead of geometric aspects as in conventional design. $\mathrm{CD}$ is also changing both design theory and practice, although most architects are not yet aware of its impact (Caetano and Leitão, 2019). All of these knowledge-based advancements should be managed into multiple levels of organizations, both within the education institutions and with the external counterparts of the construction industry to more involve information technology industry and industrial design experts, which includes the need to raise investor awareness of the benefits involved in the BIM-supported integrated design process (Filzmoser et al., 2016).

\subsection{Change Management}

The essential key and final criteria concerns the ability of an organization to manage change. The institution needs this concerted effort to make all the members believe in and be willing to embrace the innovation to excel into the sustainable development of BIM adoption. One study showed that a paradigm shift was needed in teaching and learning to more technology-based learning and the importance of multidisciplinary learning (Vimonsatit and Htut, 2016). This aspect deals mostly with overcoming the barriers among the members of an organization. For instance, the survey conducted by Babatunde and Ekundayo identified 30 barriers that can be grouped into six major factors, namely: culture change, lack of enabling environment, staff resistance and nonavailability of industrial experts, lack of accreditation standards and requirements, high cost of implementation and high risk on security concern. Some important specific barriers were lack of IT infrastructure; BIM resource-intensive; lack of government direction; the cost of staff 
/lecturers training; availability of qualified staff to take BIM courses; the need to continually upgrade the BIM software; and the lack of accreditation standards and requirements to guide the implementation of BIM within a curriculum. More detailed problems included the need for industrial involvement and lack of university management support in integrating different areas of the curriculum to realize the multidisciplinary aspects of BIM (Babatunde et al., 2018; Babatunde and Ekundayo, 2019). BIM as a complex new culture was the most commonly complained about obstacle of adoption. Such complexity particularly refers to the initial start-up of the process of the BIM setting that requires more technical attention and coordination to produce an optimal work platform in accordance with the work culture (Chen et al., 2019). Another obstacle is the interoperability of BIM which is also related to the selection of BIM tools, the selection of employment of pilot projects, the less developed risk management, and the underdeveloped guidelines and standards (Hanafi et al., 2016). Hence, we believe that it is imperative for higher institutions to convince all lecturers, technical staff members as well as students about the importance of BIM as part of the needed institutional change towards innovation. To increase the maturity of the BIM adoption, institutions will also need the managerial commitment at all levels of organizations within the institution such as heads of laboratories, study programs, departments, as well as top level university wide promoters to include BIM as one of the strategies in dealing with the Industrial Revolution 4.0. The institution may also set action plans to manage the change towards the BIM ecosystem, including developing networks, vendors, consultants, and suppliers to support BIMbased innovation. We saw that adoption of BIM in education will also open the future pathways to further innovation of new skills, praxis, and theory of $\mathrm{CD}$ in education. To accelerate the change toward innovation, multidisciplinary and interprofessional support for collaboration is an essential factor for this important final stage of adoption.

\section{MODEL OF BIM ADOPTION: CONCLUSIONS AND RECOMENDATIONS}

We have thoroughly elucidated the notion of BIM adoption in higher education, especially in architecture and generally in engineering, construction, operation, and management schools. Through historical reflective study and semisystematic literature review, we have arrived at some conclusions to answer the aforementioned research questions. From the expert discussion, we propose a BIM adoption model, conceptually comprising the three-dimensional perspectives of organizational scoping, maturity ladder, and six key criteria relevant to picture the adoption process. Those proposed six main adoption criteria are: (a) institution vision and priorities, (b) infrastructure, (c) curriculum, (d) human resources, (e) knowledge organization, and (f) change management. In each criterion, three parameters are developed to capture the readiness ladder of maturity, from preparation, implementation, and innovation level, for implementation in the higher education institution (Figure 1). Our discussions with experts and BIM implementers suggested that the model may show a comprehensive view of higher education dimensions of BIM adoption. On this basis, we recommend that higher education institutions, especially those which are still in the entry level of BIM adoption, may begin to develop a vision, strategy, and roadmap for the integration of BIM in the academic environment as soon as possible as the gap is widening between education and the demand of AECOM industry. The proposed model can provide an overview of the aspects, self-assessment tool, and guiding steps to close the gap and protect the opportunities which are at stake. 


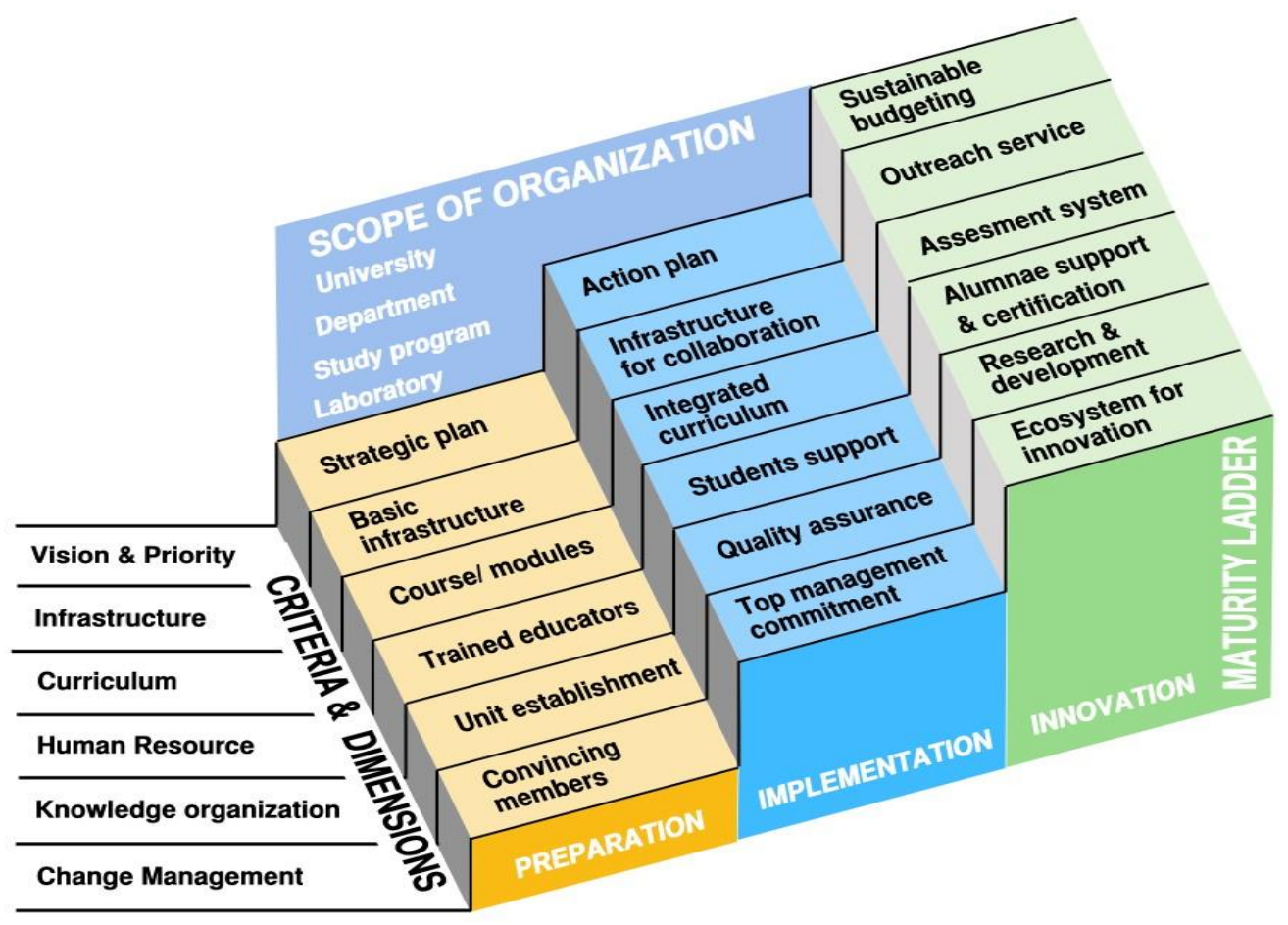

Figure 1. Concept of BIM Adoption in architectural education

The model implies the importance of infrastructure, technology, and supporting human resources not only within but also from outside the organization to develop a multidisciplinary community in operation, technical and nontechnical solutions, and research. Selected technology and infrastructure are inseparable from individual abilities and preferences although theoretically, human resources can learn new things. However, our experience proved that the more familiar technical environment will accelerate the BIM adoption process and therefore, the readiness of this infrastructure will be closely related to the readiness of trained staff in the organization.

We also noticed that some references strongly suggest that a collaborative environment in various contexts and regardless of the size of the institution is essentially important and may also accelerate the process of BIM adoption. Here, we saw that technology and infrastructure, the readiness of skilled trainers or human resources, and knowledge organization that support the entire process ranging from the preparation, learning process, evaluation, and decision- making are additional keys for the successful BIM adoption.

\section{ACKNOWLEDGMENTS}

$\mathrm{We}$, the Building Information Modelling Centre of Excellence, would like to express gratitude to Universitas Islam Indonesia for financially supporting this research under the scheme of Excellence Research of Directorate Research and Community Service. We are also indebted to the Institute BIM Indonesia (iBIMi) and to the Board of Research and Development Ministry of Public Works and Housing (Adji Krisbandono, Vicky Agustina, Galih Primanda), Amy Rachmadani (PDW Architect), Ardhanu Zunanto Hardhi (Wijaya Karya Contractor), and Riezka Hadriansyah (Hutama Karya Contractor) for the discussion. We also thank the Indonesian Association of School of Architecture for facilitating us with access to reach schools of architecture to continue this research. We convey our gratitude to Mr. Rayendra Zainal, member of the research group who passed away during the writing of this paper. 


\section{REFERENCES}

1. Abdelhameed, W. (2018), "BIM in architecture curriculum: a case study", Architectural Science Review, Taylor and Francis Ltd., Vol. 61 No. 6, pp. 480491.

2. Abdelhameed, W.A. (2013), "Virtual reality use in architectural design studios: a case of studying structure and construction", Procedia Computer Science, Vol. 25, pp. 220-230.

3. Abdirad, H. and Dossick, C.S. (2016), "BIM curriculum design in architecture, engineering, and construction education: a systematic review", Journal of Information Technology in Construction, Department of Computer Science, College of Built Environments, University of Washington, Seattle, United States, Vol. 21, pp. 250-271.

4. Abuelmaatti, A. and Ahmed, V. (2014), "Collaborative technologies for small and medium sized architecture, engineering and construction enterprises: implementation survey", Journal of Information Technology in Construction, Department of Computer Science, Blake Hall College, London, United Kingdom, Vol. 19, pp. 210-224.

5. Abuelmaatti, A. and Ahmed, V. (2018), "Collaboration environments for small and medium-sized architecture, engineering and construction enterprises: success factors in implementation", International Journal of Information Technology and Management, Inderscience Enterprises Ltd., University of Bolton, Deane Road Greater ManchesterBL3 5AB, United Kingdom, Vol. 17 No. 4, pp. 313-333.

6. Ahmad, A.M., Hafeez, M.A., Ahmad, A.M., Aliyu, A.A., Rodriguez, S. and Dawood, N. (2016), "BIM: A Disruptive Process Towards Traditional Practice", Proceedings of the 16th International Conference on Construction Applications of Virtual Reality, 11-13 December 2016, HK, No. December, pp. 80- 93.
7. Ahmed, A.L. and Kassem, M. (2018), "A unified BIM adoption taxonomy: conceptual development, empirical validation and application", Automation in Construction, Elsevier, Vol. 96 No. November 2017, pp. 103-127.

8. Ahn, E. and Kim, M. (2016), "BIM awareness and acceptance by architecture students in Asia", Journal of Asian Architecture and Building Engineering, Architectural Institute of Japan, Department of Architecture \& Architectural Engineering, Seoul National University, South Korea, Vol. 15 No. 3, pp. 419-424.

9. Aksenova, G., Kiviniemi, A., Kocaturk, T. and Lejeune, A. (2019), "From Finnish AEC knowledge ecosystem to business ecosystem: lessons learned from the national deployment of BIM", Construction Management and Economics, Vol. 37 No. 6, pp. 317-335.

10. Ambrose, M.A. (2007), "BIM and integrated practice as provocateurs of design education", Architexturez.net, pp. 283-288.

11. Ambrose, M.A. (2012), "Agent provocateur - BIM in the academic design studio", International Journal of Architectural Computing, School of Architecture, Planning and Preservation, University of Maryland, College Park, MD 20742, United States, Vol. 10 No. 1, pp. 53-66.

12. Angulo, A. (2007), "Digital media instruction in architecture education", Open House International, Texas A and M University, College Station, TX, United States, Vol. 32 No. 2, pp. 65-73.

13. Armenakis, A.A., Harris, S.G. and Mossholder, K.W. (1993), "Creating readiness for organizational change", Human Relations, SAGE Publications, Vol. 46 No. 6, pp. 681-703.

14. Babatunde, S.O. and Ekundayo, D. (2019), "Barriers to the incorporation of BIM into quantity surveying undergraduate curriculum in the Nigerian universities", Journal of 
Engineering, Design and Technology, Emerald Group Publishing Ltd., Faculty of Engineering and the Built Environment, University of Johannesburg, Johannesburg, South Africa, Vol. 17 No. 3, pp. 629-648.

15. Babatunde, S.O., Ekundayo, D., Babalola, O. and Jimoh, J.A. (2018), "Analysis of the drivers and benefits of BIM incorporation into quantity surveying profession: academia and students' perspectives", Journal of Engineering, Design and Technology, Emerald Group Publishing Ltd., Department of Quantity Surveying, Obafemi Awolowo University, Ile-Ife, Nigeria, Vol. 16 No. 5, pp. 750-766.

16. Becerik-Gerber, B., Gerber, D.J. and $\mathrm{Ku}, \quad \mathrm{K}$. (2011), "The pace of technological innovation in architecture, engineering, and construction education: Integrating recent trends into the curricula", Electronic Journal of Information Technology in Construction, Department of Civil and Environmental Engineering, School of Engineering, University of Southern California, United States, Vol. 16, pp. 411-432.

17. Bilgehan İyican, A., Emre Dinçer, A. and Bektaş, I. (2015), "A studio experience on parametric modelling approaches", Turkish Online Journal of Educational Technology, Sakarya University, Karabuk University, Turkey, Vol. 2015, pp. 51-60.

18. Bosch-Sijtsema, P. M., Gluch, P., \& Sezer, A. A. (2019). Professional development of the BIM actor role. Automation in Construction, 97(May 2018), 44-51. https://doi.org/10.1016/j.autcon.2018.10 .024 .

19. Bozoglu, J. (2016), "Collaboration and coordination learning modules for BIM education", Journal of Information Technology in Construction, Department of Computer Science, Department of Civil, Architectural, and
Environmental Engineering, Illinois Institute of Technology, Chicago, IL, United States, Vol. 21, pp. 152-163.

20. Brokbals, S. and Čadež, I. (2017), "Academic teaching of BIM development - status quo - demand for action ", Bautechnik, Wiley-VCH Verlag, Technische Universität Dortmund, Lehrstuhl Immobilienwirtschaft und Bauorganisation, August-SchmidtStraße 8, Dortmund, 44227, Germany, Vol. 94 No. 12, pp. 851-856.

21. Caetano, I. and Leitão, A. (2019), "Architecture meets computation: an overview of the evolution of computational design approaches in architecture", Architectural Science Review, Taylor and Francis Ltd., available

at:https://doi.org/10.1080/00038628.20 19.1680524.

22. Chen, Y., Yin, Y., Browne, G.J. and Li, D. (2019), "Adoption of building information Modelling in

23. Chinese construction industry: the technology-organization-environment framework", Engineering, Construction and Architectural Management, Emerald Group Publishing Ltd., Tianjin University of Technology, Tianjin, China, available at:https://doi.org/10.1108/ECAM-112017-0246.

24. Cocchiarella, L. (2016), "BIM: dimensions of space, thought, and education", Disegnarecon, University of L'Aquila, Department of Civil Construction, Building and Architecture, Environmental Engineering, Department DASTU, School AUIC, Italy, Vol. 9 No. 16, pp. 3.1-3.5.

25. Deniz, G.O. (2018), "Emerging CAD and BIM trends in the AEC education: an analysis from students' perspective", Journal of Information Technology in Construction, Department of Computer Science, College of Architecture and the Built Environment, Thomas Jefferson University, Philadelphia, PA, Vol. 23, pp. 138-156.

26. Diao, P.-H. and Shih, N.-J. (2019), "Trends and research issues of augmented reality studies in architectural and civil engineering 
education: a review of academic journal publications", Applied Sciences (Switzerland), MDPI AG, Department of Architecture, National Taiwan University of Science and Technology, 43, Section 4, Keelung Road, Taipei, 106, Taiwan, Vol. 9 No. 9, available at:https://doi.org/10.3390/app9091840.

27. Dossick, C.S., Homayouni, H. and Lee, G. (2015), "Learning in global teams: BIM planning and coordination", International Journal of Automation and Smart Technology, Chinese Institute of Automation Engineers, College of Built Environments, University of Washington, United States, Vol. 5 No. 3, pp. 119-135.

28. Filzmoser, M., Kovacic, I. and Vasilescu, D.-C. (2016), "Development of BIM-supported integrated design processes for teaching and practice", The Engineering Project Organization Journal, Vol. 6 No. 2-4, pp. 129-141.

29. Ghosh, A., Parrish, K. and Chasey, A.D. (2015), "Implementing a vertically integrated BIM curriculum in an undergraduate construction management program", International Journal of Construction Education and Research, Routledge, Arizona State University, Tempe, AZ, United States, Vol. 11 No. 2, pp. 121-139.

30. Gilkinson, N., Raju, P., Kiviniemi, A. and Chapman, C. (2015), "Building Information Modelling: The Tide is Turning", Proceedings of the Institution of Civil Engineers: Structures and Buildings, Thomas Telford Services Ltd, School of the Built Environment, University of Salford, Salford, Greater Manchester, United Kingdom, Vol. 168 No. 2, pp. 81-93.

31. Greef, G. and Ghoshal, R. (2004), Practical E-Manufacturing and Supply Chain Management, edited by Mackay, S., First edit., Newnes, Oxford, Burlington MA.

32. Gu, N. and London, K. (2010), "Understanding and facilitating BIM adoption in the AEC industry", Automation in Construction, University of Newcastle, Australia, Vol. 19 No. 8, pp. 988-999.

33. Hanafi, M.H., Sing, G.G., Abdullah, S. and Ismail, R. (2016), "Organisational readiness of building information modelling implementation: architectural practices", Jurnal Teknologi, Penerbit UTM Press, School of Housing, Building and Planning, Universiti Sains Malaysia, USMPenang 11800, Malaysia, Vol. 78 No. 5, pp. 121-126.

34. Holt, D. (2007), "Toward a comprehensive definition of readiness for change: a review of research and instrumentation", in A., A.A., Pasmore, W.A. and Woodman, R.W. (Eds.), Research in Organizational Change and Development, Vol. 16, Emerald Group Publishing Limited, pp. 289-336.

35. Holt, D.T., Armenakis, A.A., Feild, H.S. and Harris, S.G. (2007), "Readiness for organizational change: the systematic development of a scale", Journal of Applied Behavioral Science, Vol. 43 No. 2 No. June 2007, pp. 232-255.

36. Hu, M. (2019), "BIM-enabled pedagogy approach: using BIM as an instructional tool in technology courses", Journal of Professional Issues in Engineering Education and Practice, American Society of Civil Engineers (ASCE), School of Architecture, Planning, and Preservation, Univ. of Maryland, 3835 Campus Dr., College Park, MD 20742, United States, Vol. 145 No. 1, available at:https://doi.org/10.1061/(ASCE)EI.19 43-5541.0000398.

37. Huang, Y. (2018), "Developing a threelevel framework for building information Modelling education in construction management", Universal Journal of Educational Research, Horizon Research Publishing, Department of Construction \& Operations Management, South Dakota State University, Brookings, SD 57007, United States, Vol. 6 No. 9, pp. 19912000.

38. Jagiello-Kowalczyk, M. (2017), "Integration of sustainable design issues from the first stage of the education process of architecture students", World Transactions on Engineering and Technology Education, World Institute for Engineering and Technology Education, Cracow University of Technology, Kraków, Poland, Vol. 15 No. 1, pp. 23-27.

39. Jagiełło-Kowalczyk, M. and Jamrozy, M. (2016), "Education of architects in the field of BIM technology", Global 
Journal of Engineering Education, World Institute for Engineering and Technology Education, Cracow University of Technology, Kraków, Poland, Vol. 18 No. 3, pp. 180-185.

40. Jin, R., Yang, T., Piroozfar, P., Kang, B.-G., Wanatowski, D., Hancock, C.M. and Tang, L. (2018), "Project-based pedagogy in interdisciplinary building design adopting BIM", Engineering, Construction and Architectural Management, Emerald Group Publishing Ltd., Department of Built Environment, University of Brighton, Brighton, United Kingdom, Vol. 25 No. 10, pp. 1376-1397.

41. Jin, R., Zou, Y., Gidado, K., Ashton, P. and Painting, N. (2019), "Scientometric analysis of BIM-based research in construction engineering and management", Engineering, Construction and Architectural Management, Emerald Group Publishing Ltd., School of Environment and Technology, University of Brighton, Brighton, United Kingdom, available

at:https://doi.org/10.1108/ECAM-082018-0350.

42. Joannides, M.M., Svetlana, O. and Issa, R.R.A. (2012), "Implementation of Building Information Modelling into accredited programs in architecture and construction education", International Journal of Construction Education and Research, Routledge, Vol. 8 No. 2, pp. $83-100$.

43. Juan, Y.-K., Lai, W.-Y. and Shih, S.-G. (2017), "Building Information Modelling acceptance and readiness assessment in Taiwanese architectural firm", Journal of Civil Engineering and Management, Vol. 23 No. 3, pp. 356367.

44. Kassem, M. and Succar, B. (2017), "Macro BIM adoption: comparative market analysis", Automation in Construction, Vol. 81 No. May, pp. 286-299.

45. $\mathrm{Ku}, \mathrm{K}$. and Mahabaleshwarkar, P.S. (2011), "Building interactive Modelling for construction education in virtual worlds", Electronic Journal of Information Technology in Construction, Department of Building Construction, School of Construction,
Virginia Tech, United States, Vol. 16, pp. 189-208.

46. Leite, F. (2016), "Project-based learning in a building information Modelling for construction management course", Journal of Information Technology in Construction, Department of Computer Science, Department of Civil, Architectural and Environmental Engineering, University of Texas at Austin, United States, Vol. 21, pp. 164176.

47. Lokuge, S., Sedera, D., Grover, V. and Dongming, X. (2019), "Organizational readiness for digital innovation: development and empirical calibration of a construct", Information and Management, Vol. 56 No. 3, pp. 445461.

48. Lu, W., Peng, Y., Shen, Q. and Li, H. (2013), "Generic model for measuring benefits of BIM as a learning tool in construction tasks", Journal of Construction Engineering and Management, Building Information Modelling (BIM) Laboratory, Dept. of Real Estate and Construction, Univ. of Hong Kong, Hong Kong, Vol. 139 No. 2, pp. 195-203.

49. MacLaren, A.J.W., Wilson, M., Simmonds, R., Hamilton-Pryde, A., McCarthy, J. and Milligan, A. (2017), "Educating students for the collaborative workplace: facilitating interdisciplinary learning in construction courses", International Journal of Construction Education and Research, Routledge, Vol. 13 No. 3, pp. 180-202.

50. Nushi, V. and Basha-Jakupi, A. (2017), "The integration of BIM in education: a literature review and comparative context", Global Journal of Engineering Education, World Institute for Engineering and Technology Education, University of Pristina Hasan Prishtina, Pristina, Kosovo, Serbia, Vol. 19 No. 3, pp. 273-278.

51. Olowa, T.O.O., Witt, E. and Lill, I. (2019), "BIM for Construction Education: Initial Findings from a Literature Review", Lill, I. and Witt, E. (Ed.) 10th Nordic Conference on Construction Economics and Organization (Emerald Reach Proceedings Series, Vol. 2), Emerald 
Publishing Limited, pp. 305-313. https://doi.org/10.1108/S2516285320190000002047.

52. Palomera-Arias, R. and Liu, R. (2016), "BIM laboratory exercises for a MEP systems course in a construction science and management program", Journal of Information Technology in Construction, Department of Computer Science, Department of Construction Science, University of Texas at San Antonio, San Antonio, TX, United States, Vol. 21, pp. 188-203.

53. Poirier, E.A., Staub-French, S. and Forgues, D. (2015), "Measuring the impact of BIM on labor productivity in a small specialty contracting enterprise through action-research", Automation in Construction, Elsevier, Vol. 58, pp. 7484.

54. Rosli, M.F., Razak, A.S. and Amer Younus, M. (2016), "To BIM or not to BIM: a pilot study on University of Malaya's architectural students' software preference", Journal of Design and Built Environment, University of Malaya, Department of Architecture, Faculty of Built Environment, University of Malaya, Kuala Lumpur, Malaysia, Vol. 16 No. 1, pp. 13-26.

55. Sacks, R. and Barak, R. (2010), "Teaching Building Information Modelling as an integral part of freshman year civil engineering education", Journal of Professional Issues in Engineering Education and Practice, Technion-Israel Institute of Technology, Faculty of Civil and Environment Engineering, Haifa 32000, Israel, Vol. 136 No. 1, pp. 30-38.

56. Schober, K.-S., Hoff, P., Lecat, A., Thieulloy de, G. and Siepen, S. (2017), "Turning point for the construction industry: the disruptive impact of Building Information Modelling (BIM) management summary", Roland Berger Focus, September.

57. Shelbourn, M., Macdonald, J., McCuen, T. and Lee, S. (2017), "Students' perceptions of BIM education in the higher education sector: a UK and US perspective", Industry and Higher Education, SAGE Publications Ltd, University of Salford, United Kingdom, Vol. 31 No. 5, pp. 293-304.
58. Simeone, D., Cursi, S. and Acierno, M. (2019), "BIM semantic-enrichment for built heritage representation", Automation in Construction, Elsevier, Vol. 97 No. November 2016, pp. 122 137.

59. Smith, P. (2014), "BIM implementation - Global strategies", Procedia Engineering, Vol. 85, pp. 482-492.

60. Solnosky, R., Parfitt, M.K. and Holland, R. (2015), "Delivery methods for a multi-disciplinary architectural engineering capstone design course", Architectural Engineering and Design Management, Taylor and Francis Ltd., Department of Architectural Engineering, The Pennsylvania State University, 104 Engineering Unit A, University Park, PA 16802 (814) 8656394, United States, Vol. 11 No. 4, pp. 305-324.

61. Solnosky, R., Parfitt, M.K. and Holland, R.J. (2014), "IPD and BIM-focused capstone course based on AEC industry needs and involvement", Journal of Professional Issues in Engineering Education and Practice, American Society of Civil Engineers (ASCE), Pennsylvania State Univ., University Park, PA 16802, United States, Vol. 140 No. 4, available at:https://doi.org/10.1061/(ASCE)EI.19 435541.0000157.

62. Son, H., Lee, S. and Kim, C. (2015), "What drives the adoption of Building Information Modelling in design organizations?: an empirical investigation of the antecedents affecting architects' behavioral intentions", Automation in Construction, Elsevier, Vol. 49 No. PA, pp. 92-99. https://doi.org/10.1016/j.autcon.2014.1 0.012 .

63. Succar, B. and Kassem, M. (2015), "Macro-BIM adoption: conceptual structures", Automation in Construction, Elsevier, Vol. 57 pp. 64$79 \quad$ available at:https://doi.org/10.1016/j.autcon.2015 .04 .018 .

64. Suwal, S. and Singh, V. (2018), “Assessing students' sentiments towards the use of a Building Information Modelling (BIM) learning platform in a construction project 
management course", European Journal of Engineering Education. Vol 43 No. 4, pp. 492-506, https://doi.org/10.1080/03043797.2017. 1287667.

65. Uhm, M., Lee, G. and Jeon, B. (2017), "An analysis of BIM jobs and competencies based on the use of terms in the industry", Automation in Construction, Elsevier, Vol. 81 No. October 2016, pp. 67-98 https://doi.org/10.1016/j.autcon.2017.0 6.002.

66. Vassigh, S., Davis, D., Behzadan, A.H., Mostafavi, A., Rashid, K., Alhaffar, H., Elias, A., et al. (2020), Teaching Building Sciences in Immersive Environments: A Prototype Design, Implementation, and Assessment, International Journal of Construction Education and Research, 16:3, 180-196, https:doi.org/10.1080/15578771.2018.1 525445.

67. Vimonsatit, V. and Htut, T. (2016), "Civil Engineering students' response to visualisation learning experience with building information model", Australasian Journal of Engineering Education, Vol. 21 No. 1, pp. 27-38.

68. Wang, L. \& Leite, F. (2014), "Processoriented approach of teaching Building Information Modelling in construction management", Journal of Professional Issues in Engineering Education and Practice, American Society of Civil Engineers (ASCE), Dept. of Civil, Architectural and Environmental Engineering, Univ. of Texas at Austin, 1 University Station C1752, Austin, TX 78712, United States, Vol. 140 No. 4, https://doi.org/10.1061/(ASCE)EI.1943 $-5541.0000203$.

69. Wang, H., \& Meng, X. (2019). Transformation from IT-based knowledge management into BIMsupported knowledge management: a literature review. Expert Systems with Applications, 121, 170-187. https://doi.org/10.1016/j.eswa.2018.12. 017.

70. Wang, H., Pan, Y. and Luo, X. (2019), "Integration of BIM and GIS in sustainable built environment: a review and bibliometric analysis", Automation in Construction, Elsevier, Vol. 103 No. September 2018, pp. 41-52, https://doi.org/10.1016/j.autcon.2019.0 3.005.

71. Wang, P., Wu, P., Wang, J., Chi, H.-L. and Wang, X. (2018), “A critical review of the use of virtual reality in construction engineering education and training", International Journal of Environmental Research and Public Health, MDPI AG, School of Engineering and Technology, Southwest University, Chongqing, 400715, China, Vol. 15 No. 6, https://doi.org/10.3390/ijerph15061204

72. Weiner, B.J. (2009), "A theory of organizational readiness for change.", Implementation Science, England, Vol. 4, p. 67.

73. Wong, K.-D.A., Wong, K.W.F. and Nadeem, A. (2011), "Building Information Modelling for tertiary construction education in Hong Kong", Electronic Journal of Information Technology in Construction, Department of Building and Real Estate, Hong Kong Polytechnic University, Hong Kong, Hong Kong, Vol. 16, pp. 467-476.

74. Wu, T.-H., Wu, F., Liang, C.-J., Li, Y.F., Tseng, C.-M. and Kang, S.-C. (2019), "A virtual reality tool for training in global engineering collaboration", Universal Access in the Information Society, Springer Verlag, Department of Civil Engineering, National Taiwan University, No. 1, Sec. 4, Roosevelt Rd., Taipei, Taiwan, Vol. 18 No. 2, pp. 243-255.

75. Wu, W. and Issa, R.R.A. (2014), "BIM education and recruiting: survey-based comparative analysis of issues, perceptions, and collaboration opportunities", Journal of Professional Issues in Engineering Education and Practice, American Society of Civil Engineers (ASCE), Construction Management Program, CSU Fresno, 2320 E. San Ramon Ave., Fresno, CA 93740, United States, Vol. 140 No. 2, available at:https://doi.org/10.1061/(ASCE)EI.19 43-5541.0000186.

76. Yan, W., Culp, C. and Graf, R. (2011), "Integrating BIM and gaming for realtime interactive architectural visualization", Automation in 
Construction, Department of Architecture, Texas A and $\mathrm{M}$ University, 3137 TAMU, College Station, TX 77845, United States, Vol. 20 No. 4, pp. 446-458.

77. Yusuf, B.Y., Embi, M.R. and Ali, K.N. (2017), "Academic readiness for Building Information Modelling

78. (BIM) integration to Higher Education Institutions (HEIs) in Malaysia", International Conference on Research and Innovation in Information Systems, ICRIIS, available at:https://doi.org/10.1109/ICRIIS.2017. 8002491.

79. Zhang, J., Xie, H. and Li, H. (2018), "Project based learning with implementation planning for student engagement in BIM classes", International Journal of Engineering Education, Tempus Publications, School of Economic and Management,
Chang'an University, Middle Section of Nanerhuan Road, Yanta District, Xi'an, 710064, China, Vol. 35 No. 1, pp. 310322.

80. Zou, P.X.W., Xu, X., Jin, R., Painting, N. and Li, B. (2019), "AEC students' perceptions of BIM practice at Swinburne University of Technology", Journal of Professional Issues in Engineering Education and Practice, American Society of Civil Engineers (ASCE), Dept. of Civil and Construction Engineering, Swinburne Univ. of Technology, Hawthorn Campus, Hawthorn, VIC 3122, Australia, Vol. 145 No. 3, available at: https://doi.org/10.1061/(ASCE)EI.1943 -5541.0000410 . 